\title{
Focus on the Gut-Kidney Axis in Health and Disease
}

\author{
Elisavet Stavropoulou ${ }^{1,2 *}$, Konstantia Kantartzi ${ }^{3 *}$, Christina Tsigalou ${ }^{3}$, \\ Theoharis Konstantinidis ${ }^{3}$, Gioulia Romanidou ${ }^{4}$, Chrysa Voidarou ${ }^{5}$ and \\ Eugenia Bezirtzoglou ${ }^{3}$
}

${ }^{1}$ Centre Hospitalier Universitaire Vaudois (CHUV), Lausanne, Switzerland, ${ }^{2}$ Department of Infectious Diseases, Central Institute, Valais Hospital, Sion, Switzerland, ${ }^{3}$ Department of Medicine, Democritus University of Thrace, Alexandroupolis, Greece, ${ }^{4}$ Hospital "Sismanoglio", Komotini, Greece, ${ }^{5}$ Department of Public Health P.U., Arta, Greece

\section{OPEN ACCESS}

Edited by:

Tara Sigdel,

University of California, San Francisco,

United States

Reviewed by:

Maria J. Stangou,

Aristotle University of

Thessaloniki, Greece

Hee-Seong Jang,

University of Nebraska Medical

Center, United States

*Correspondence:

Elisavet Stavropoulou elisabeth.stavropoulou@gmail.com

Konstantia Kantartzi

kkantart@med.duth.gr

Specialty section:

This article was submitted to Nephrology,

a section of the journa

Frontiers in Medicine

Received: 21 October 2020 Accepted: 16 December 2020 Published: 21 January 2021

Citation:

Stavropoulou E, Kantartzi K,

Tsigalou C, Konstantinidis T, Romanidou G, Voidarou $C$ and Bezirtzoglou E (2021) Focus on the

Gut-Kidney Axis in Health and Disease. Front. Med. 7:620102. doi: 10.3389/fmed.2020.620102
The recent new developments in technology with culture-independent techniques including genome sequencing methodologies shed light on the identification of microbiota bacterial species and their role in health and disease. Microbiome is actually reported as an important predictive tool for evaluating characteristic shifts in case of disease. Our present review states the development of different renal diseases and pathologies linked to the intestinal dysbiosis, which impacts on host homeostasis. The gastrointestinal-kidney dialogue provides intriguing features in the pathogenesis of several renal diseases. Without any doubt, investigation of this interconnection consists one of the most cutting-edge areas of research with potential implications on our health.

Keywords: gut, kidney, gut-kidney axis, microbiome, health, disease

\section{INTRODUCTION}

Newborns' intestinal colonization established either by vaginal delivery or by cesarean section has been extensively studied $(1,2)$. Multiple factors such as immune system, diet, environment, and genetic endowment are involved in the development of the newborn's intestinal microbiota. Moreover, other endogenous and exogenous factors such as hospital personnel, infections, stress, vaccination, personal habits, hormonal status, and age (3-5) are entailed in the processes of the microbiome establishment. To these issues, new technological breakthroughs such as next-generation sequencing of the $16 \mathrm{~S}$ ribosomal RNA gene (rRNA) and metagenomics whole-genome shotgun sequencing advanced and enlightened our knowledge on the intestinal microbiome and the barrier effect repulsing pathogenic bacteria from gut colonization. The $16 \mathrm{~S}$ rRNA technologies provided taxonomic resolution of bacterial communities at species and strains level (6). Gut bacterial communities participate dynamically in the metabolism and immune system education and erect potent positive or negative interconnections between bacteria and other systems. These interconnections are bidirectional and reported collectively as the gut-kidney axis. The fecal microbiota composition and functionality seem to play a crucial role in the homeostasis but also in the development of kidney diseases. Although there is a knowledge gap on the different interplay components between gut microbiome and organs that needs to be completely clarified, hopefully technological advancements can permit us to better appreciate this multifaceted issue $(6,7)$. Our present review promotes recent knowledge that certainly will stimulate more study and research on the involved complicate pathways of the gut-kidney axis.

\section{Summarizing the Gut Microbiome}

As known, there is a plethora of studies on the human gut microbiome as it is one of the richest in population microbiomes of human body (8-11). Without any doubt, the gut keeps a key role 
in nutrients absorption and substances synthesis such as vitamins, amino acids, and enzymes, as well as production of short-chain fatty acids (SCFAs) (12). Acetate, butyrate and propionate are SCFAs coming from bacterial carbohydrate fermentation, and they represent energy sources in the colon (13). Specifically, they enhance epithelial integrity by providing energy to epithelial cells, they participate in the immunomodulation processes, and finally they act as a shield against pathogenic bacteria (13). Two main signaling mechanisms are taken through SCFAs (14): the activation of G-protein-coupled receptors (GPCRs) and the inhibition of histone deacetylases (HDACs) (14). GPCRs are receptors of SCFAs and involved in the processes of metabolism, inflammation, and disease generally. Yet, the free fatty acid receptor-2 and-3 (FFAR2 and FFAR3) where SCFAs are activated are located in multiple human sites including gut and participate in the regulation of metabolism (15). Yet, SCFAs affect the physiology of the gut epithelial cells by inhibition of HDACs leading to chromatin remodeling and shifts in transcription processes (16). HDACs showed antiproliferative and anti-inflammatory outcomes in vitro- and in vivo-developed models of inflammation (16).

As defined recently (17), the intestinal microbiome is composed by microorganisms, bacteria, viruses, protozoa, and fungi, as well as of their genetic equipment. It is believed that the human gut microbiome contains more than 3.3 million prokaryotic genes (18).

To this point, the Human Microbiome Project in the United States [US National Institutes of Health (NIH), http:// commonfund.nih.gov/hmp/] (19) and the metaHIT Consortium (20) in Europe have been able to characterize the composition of bacterial communities at the various human ecosystems. In addition, the MetaHIT project classified bacterial populations in three different enterotypes (21). Initially, those projects were focused on the gut intestinal microbiotas and other open human sites due to the facility in collecting samples. Enterotype 1 features by high Bacteroides levels and enterotype 3 by high Ruminococcus levels. Enterotype 2 showed important Prevotella population and few Bacteroides. Yet, these enterotypes are not influenced by age, ethnicity, gender, and body weight (22). Diet seems to be a crucial factor to the gut microbiome identity. Western diet plenty of proteins and fats showed domination of Bacteroides, whereas diet rich in carbohydrates and fibers of Prevotella species (22).

In short, the gut microbiota contains four bacterial groups called phylum, which are Firmicutes, Bacteriodetes, Actinobacteria, and Proteobacteria (23).

Notably, the evolution of the gut microbiome and its shifting were extensively studied from newborn to the adult age $(1-3,8-$ 10). Multiple factors influence the magnitude of the bacterial mosaic, which is in perfect balance in healthy people in a state called symbiosis $(4,5)$. Stress, feeding, environment, hormones, and genetic predisposition are stated as important determinants $(4,5,11)$. However, when disruption of this balance occurs, dysbiosis is installed, which is shown to be closely associated with disease (23-25).

\section{The Urinary Microbiome in Health}

Although our subject is not based on the role of the urinary microbiome, we included this part of knowledge as wiping back to front the urinary tract is in close continuity with the kidney.

The study and the importance of the urinary tract microbiome aroused interest during recent years $(26,27)$. In contrast to the old belief that the urinary tract is sterile (28) recent studies demonstrated that the urinary tract possesses a unique microbiota (28) with a dynamic role in the maintaining of urinary health due to its metabolic capacity.

The urinary system is constituted of the kidneys, ureters, the urinary bladder, and the urethra. Ascendant microbial populations following lower urinary tract infections as bladder cystitis may cause kidney infections.

The kidneys are the seat of the urinary system primary functions as they are the site of blood filtering, electrolyte balance, and maintaining water. Kidney is considered sterile in both men and women. Bacteria found at sites distal to the kidney, bladder, and urethra seem to influence the urologic health in multiple ways. Besides, the gut microbiome carries complex and dynamic microbiota influencing human physiology, nutrition, and immunity. When disruption of this microbiota occurs, microbial communities are imbalanced, and there is a rupture of the interconnection between these microbial communities and human cells, resulting in health disorders.

It is of note that the urinary tract was not entered initially in the global Human Microbiome study as it was considered immoral and unethical to proceed to bladder biopsies or suprapubic aspirates from healthy persons in order to characterize $(26,28)$ the microbiota composition. Lactobacillus and Streptococcus were the genera most frequently reported in the urinary microbiota (26).

Klebsiella, Rhodanobacter, Saccharofermentans, Jonquetella, Alloscardovia, Burkholderia, and Veillonella were also isolated from the urinary microbiota (26). It is of note that Parvimonas, Jonquetella, Saccharofermentans, and Proteiniphilum genera were found in individuals older than 70 years (29).

Surprisingly, some bacteria genera were detected only by cultures (Trueperella), whereas other genera only via sequencing methods (Atopobium) (30). Methodologies limitations should explain these differences as several bacterial strains are not growing in expanded quantitative urine culture (27), and also the $16 \mathrm{~S}$ rRNA sequencing is not distinguishing between living and dead bacteria (31). Nevertheless, scientists underpin the importance of $16 \mathrm{~S}$ rRNA sequencing as it combines presence of living and dead bacteria as an imprint of the microbes that once prevailed in the microbiota (19). Furthermore, collection of middle stream urine, which is considered overall sterile, using the 16S rRNA sequencing, showed (32) predominance of Lactobacillus in women and Corynebacterium in men. Certainly, the above results are at least expected, due first to the shortness and proximity of the female urethra to the vagina where important populations of Lactobacillus inhabit and second to the anatomic structure of the male genital system, which is housed by Corynebacterium coming probably from the skin microflora (33). 


\section{The Gut-Kidney Axis}

As discussed previously, when microbial communities are imbalanced, the disruption of the normal gut microbiota may lead to intestinal dysbiosis due to the breaching of the intestinal barrier. Moreover, it is reported that passage of viable bacteria may occur from the gut to other extraintestinal sites including the kidney. This bacterial translocation may be associated with bacterial dysbiosis, bacterial overgrowth, and low host immune defense (34-36).

The gut microbiota produces many uremic solutes and toxins, such as indoxyl sulfate, $p$-cresyl sulfate (PCS), and trimethylamine (TMA) N-oxide during chronic kidney disease (CKD). Yet, increasing urea concentration leads reciprocal to the intestinal microbiota alteration (37). Uremic toxins may cause renal anemia, pruritus, fatigue, mineral bone disorder, neurological damage, and cardiovascular impairment in CKD patients (37).

The pathogenic interconnection between gut microbiota and kidney diseases is called the gut-kidney axis (Figure 1) and seems to be implicated in a wide range of clinical manifestations such as CKD, acute kidney injury (AKI), hypertension, nephrolithiasis, immunoglobulin A (IgA) nephropathy, hemodialysis, and peritoneal dialysis $(7,37)$.

Technological advances in metagenomics-metabolomics reveal the contribution of the gut- kidney axis on different kidney pathologies as they help us to get a more comprehensive knowledge of the microbiome. However, the underlying mechanisms between gut microbiome and host in health and disease remain obscure. Therefore, the know-how of this interconnection may clarify disease etiologies and pathogenesis.

\section{Metabolic and Immune Pathways Involved in Kidney Diseases}

Gut microbiota has deployed a holistic shield system, which assignment is either to identify and attack the aggressors or to develop mechanisms allowing settlement of damaging (3). In this vein, the host immune system plays a crucial role to preserve the microbial intestinal balance via the barrier effect (3). Bacteria of our microbiome are tightly attached to the gut mucosa and inhibit colonization by pathogenic bacteria; this is the "colonization resistance." This is a biological barrier, and bacteria support themselves by producing antimicrobial proteins (AMPs) via Paneth cells, either by yielding SCFAs $(12,16)$. Notably, the gut microbiome through its intestinal barrier regulates homeostasis and function of both innate and adaptive immune systems locally and systemically (38). Moreover, a physical barrier seems to be evident in the barrier concept, as gut epithelial cells through apical tight junctions (TJs) transmembrane proteins form a shield preventing free diffusion from lumen to lamina propria $(3,14)$. The gut microbiota is reported to be in strait relation with the mucosal immune system (14) as gut bacteria and their toxins can cross this mucosa and spread in the bloodstream, tissues, and organs when this barrier is breached (3).

Last but not least, the activation of an immune barrier is taking place in order to preserve homeostasis $(3,14)$.
When barrier is ruptured "leaky gut" immune cells are activated, infiltrate the kidney, and induce proinflammatory and anti-inflammatory functions, as well as regulatory signals to modulate the neutrophil response (39). Neutrophils and macrophages are implicated in the innate immunity as first-line response of non-specific defense against pathogens (40). Decrease of the phagocytic capacity of macrophages impacts negatively the kidney function and produces a chronic inflammation status (40). Innate immunity keeps a crucial potential in many renal diseases (41).

The key role of the pattern recognition receptors (PRRs) in the innate immune response and their expression during inflammation was revealed (42). Notably, monocytes, neutrophils, and macrophages amplify PAMPs (pathogenassociated molecular patterns) and DAMPs (danger- associated molecular patterns) (43) triggering immune response. Scientists have studied PRRs with a special focus on TLRs (Toll-like receptors), which are membrane glycoproteins (42). TLRs are expressed in renal cells inducing activation of mitogen-activated protein kinases, nuclear factor- $\kappa \mathrm{B}(\mathrm{NF}-\kappa \mathrm{B})$, and activator protein-1 $(44,45)$.

It is of note that PRRs can be involved in the exacerbation of infection-mediated renal disease, but equally to lupus nephritis by recognition of nucleosomal autoantigens (46).

Renal tubular epithelial cells are also participants in immunity by production of chemokines, cytokines, and antimicrobial compounds (47). These cells keep an important role in inflammation processes as they could regulate positively or negatively T-cell responses as they express costimulators of T cells (ICOS-L) and B7-H1 molecules (48).

Likewise, dendritic cells (DCs), macrophages, and $\mathrm{T}$ regulatory cells (Tregs) contribute to evoke an adaptive immune response (39). Activation of DCs results in production of proinflammatory cytokines such as interleukin 12 (IL-12), IL-6 (39). Specifically, DCs induce the differentiation of naive $\mathrm{CD} 4^{+}$ $\mathrm{T}$ cells into regulatory $\mathrm{T}$ (Treg) cells and the maturation of $\mathrm{B}$ cells into IgA-secreting cells $(39,49)$.

Yet, there is a DC-mediated recruitment of Tregs, depending on the activation of alternate autophagy pathways (50). Treg recruitment seems to be a strategic point to protect from inflammation and amplify homeostasis by boosting microbiome (51).

In assistance of the above, the activity of T helper 17 (Th17) cells, a subset CD4 T helper ( Th) cells, is designated by secretion of the proinflammatory IL-17 $(49,52)$.

Likewise, renal tubular epithelial cells release NF- $\kappa$, which controls proinflammatory response (53).

To this end, the innate lymphoid cells (ILCs) act by tampering macrophage production of the proinflammatory cytokines IL$1 \beta$, IL-12, IL-23, IL-22, and interferon $\gamma(49,54)$. In this light, it is shown that the aryl hydrocarbon receptor of IL22 in ILC response (ILC3) contributes to the extinction of inflammatory Th17 cell responses that maintains Treg-mediated gut homeostasis (55). Moreover, the suppression of Th17 cells in the gut promotes their translocation and activation in kidney (49). Intestinal Th cells can be activated in the kidney via a CCL20/CCR6 axis (56). 


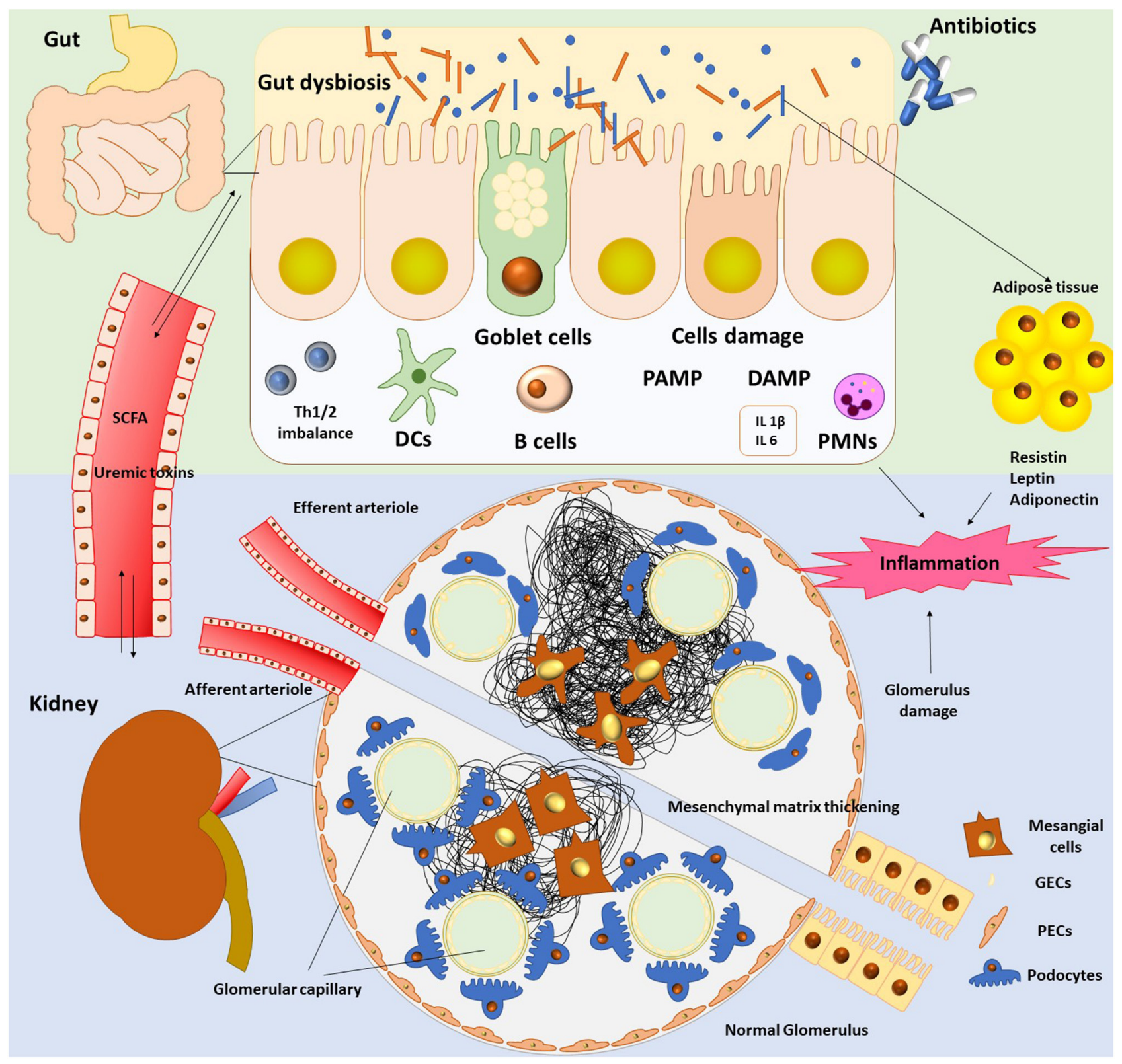

FIGURE 1 | The gut-kidney axis.

The gut microbiota interacts by means of microbial-associated molecular patterns (MAMPs) or SCFAs, as well to reduce inflammation in kidney (57). Expression of 4 receptors (GPR41, GPR43, Olfr78, and GPR109a) is found in kidney by reverse transcriptase-polymerase chain reaction (PCR) (58) associated with distinct pathological states $(59,60)$. SCFAs affect upon kidney injury by regulating inflammation (57). Administration of SCFAs in animals seems to decrease levels of reactive oxygen species, as well as cytokines production (61). Additionally, activation of NF- $\kappa \mathrm{B}$ was suspended in renal epithelial cell and low amounts of mRNA of the TLR4 were found in animals undertaken SCFAs $(49,61)$. Finally, maturation of DCs was also suspended, and differentiation of naive CD4+ T cells into Treg cells, as well as the maturation of B cells into IgA-secreting cells, was inhibited $(49,61)$. To this end, SCFAs modulated the hypoxia effects produced in renal epithelial cells by boosting biogenesis of mitochondria, and thus, their possible role as a new therapeutic agent should be challenging $(49,61)$.

Moreover, as stated, production of AMPs and IgA by Paneth cells in the gut contributes to the host microbiota balance $(62,63)$.

Lactobacillales in the gut can boost Treg cells and damper disease-causing Th17 cells in kidney of lupus mice models in order to impair inflammation (64). Owing to the above, strategies focusing on the microbiota modulation could be challenging. 
TABLE 1 | Shifts of bacterial taxa in certain kidney or kidney-associated diseases.

\begin{tabular}{|c|c|c|}
\hline Health disorder & Population increase & Population decrease \\
\hline $\begin{array}{l}\text { Chronic kidney disease } \\
\text { (CKD) }\end{array}$ & $\begin{array}{l}\text { Bacteroidetes, } \\
\text { Proteobacteria, } \\
\text { Actinobacteria }\end{array}$ & Firmicutes \\
\hline Kidney stones presence & Bacteroidetes, Firmicutes & \\
\hline $\begin{array}{l}\text { End-stage renal disease } \\
\text { (ESRD) hemodialysis }\end{array}$ & $\begin{array}{l}\text { Proteobacteria, Firmicutes, } \\
\text { Actinobacteria }\end{array}$ & \\
\hline ESRD peritoneal dialysis & Firmicutes, Actinobacteria & \\
\hline Obesity & $\begin{array}{l}\text { Bacteroidetes, } \\
\text { Proteobacteria, }\end{array}$ & Firmicutes \\
\hline $\begin{array}{l}\text { Immunoglobulin A } \\
\text { nephropathy }\end{array}$ & $\begin{array}{l}\text { Actinobacteria, } \\
\text { Proteobacteria, }\end{array}$ & \\
\hline Diabetes & $\begin{array}{l}\text { Bacteroidetes, } \\
\text { Proteobacteria }\end{array}$ & $\begin{array}{l}\text { Firmicutes, } \\
\text { Actinobacteria }\end{array}$ \\
\hline Transplanted patients & $\begin{array}{l}\text { Proteobacteria, } \\
\text { Bacteroidetes (acute } \\
\text { rejection) }\end{array}$ & $\begin{array}{l}\text { Firmicutes, } \\
\text { Actinobacteria }\end{array}$ \\
\hline Autoimmune disorders & Bacteroidetes, Firmicutes & Actinobacteria \\
\hline
\end{tabular}

\section{Microbiota and Disease States Chronic Kidney Disease}

CKD is the loss of kidney function, and it is a severe health issue. Progressive loss or failure of kidney function has an effect on the blood concentration of different noxious substances (65), which are usually metabolized and excreted by the kidney. These substances, as well as high urea concentrations, accumulate in blood and causes uremia (65). Several gut bacteria possessing ureases are able to convert urea to ammonia.

This conversion leads to shifts of the luminal $\mathrm{pH}$, resulting in uremic enterocolitis. However, there is a reciprocal process as high urea concentration enhances urease-producing bacterial growth. Heavy urea concentrations modify the biochemical environment of the intestine.

Researchers evaluated the gut microbiome in relation to the kidney disease and the development of kidney stones (66) (Table 1). Adults with kidney disease housed a microbiota characterized by an enhanced number of Enterobacteriaceae and Streptococcaceae, in contrast to the dropping populations of Prevotellaceae and Roseburia (23). Concerning adults developing kidney stones, a varied microbial community of Bacteroides, Enterobacter, Lachnospiraceae NK4A136 group, Christensenellaceae, Ruminiclostridium 5 group, Dorea, and its genus Christensenellaceae $R 7$ group is present (66).

As stated in patients with CKD, dysbiosis leads to the release of uremic toxins (67). Recent research associated gut-derived uremic toxins with the progression of CKD, cardiovascular disease, and mortality (68). In fact, higher numbers of uricase and urease-producing bacteria as well as indole- and p-cresylforming enzymes bacteria are found in subjects with endstage renal disease (ESRD) (37). Proteobacteria, Firmicutes, and Actinobacteria taxa are observed in high numbers at the $\operatorname{ESRD}(69)$.

CKD breaches the balance between normal microbiota and pathogens and permits pathogens' overgrowth. As a result, breakdown of the intestinal barrier occurs because of the rupture of the epithelial tight junctions (ETJs). ETJs are protein complexes that prevent leakage of solutes and water by forming selective channels (70). Thus, there is loss of the intestinal permeability permitting bacteria to translocate to other organs (34). Evidence in uremic rats showed bacterial translocation across the intestinal wall in the mesenteric lymph nodes (71).

Moreover, lipopolysaccharides (LPSs) originating from the cell wall of Gram-negative bacteria increase the gut TJ permeability by enhancing the enterocyte membrane TLR4 and CD14 expression (72). Additionally, LPS could mobilize the innate immune cells through TLR4 and NF-кB pathways (72). As inflammation, oxidative stress and impairment of the immune response occur; there is release of inflammatory cytokines due to the stimulation of DCs by pathogens and activation of the Th17/Th1 T-cell response $(49,53,72)$.

In the intestine, there is prevalence of anaerobic bacteria that are metabolizing in absence of $\mathrm{O}_{2}$, a process called fermentation, the different substances imported with food. In fact, there is fermentation of the amino acids' tyrosine to $p$-cresol and tryptophan to indole (73).

Those compounds should be further metabolized in the liver to PCS and p-indoxyl sulfate (IS) and TMA n-oxide (TMAO) before circulating free or serum proteins-binded (73). The above noxious uremic toxins are eliminated by tubular secretion in the kidneys; their increased levels are indicative of renal failure and progression of CKD (73). These toxins have deleterious effects on different body tissues as renal tubular cell damage, coagulation disturbances, leukocyte activation, endothelial dysfunction, cardiac fibrosis, cardiac hypertrophy, cardiovascular disease, cardiovascular mortality, atherosclerosis, insulin resistance, and reduction of fat mass (73). It is of note also that due to the prevailing oxidative stress in osteoblasts, IS impedes bone formation, which contributes to metabolic bone disease (74).

Therefore, because of the dysbiosis (37), the beneficial microbiota dominated by Bifidobacterium and Lactobacillus disappear gradually, and a dropping in SCFAs and bile acid levels is observed due to the microbiota shifting and pathogen dominance (75). SCFAs and specifically butyrate are important energy sources for colonocytes (76) and also play an important role in the epithelial integrity. Moreover, activation of the SCFA receptor GPR109A is linked to the suppression of several proinflammatory mediators (76).

Authors reported (77) decrease in the anaerobic microflora in patients with CKD, while an increase of the aerobic microflora background (78) is observed with a predominance of Enterobacteriaceae (79). As previously discussed gut microbiota in healthy recipients possess three main enterotypes (80): Bacteroides, Prevotella, or Ruminococcus. As previously stated, the gut microbiota in patients with CKD is shifted, characterized by low numbers of Lactobacillaceae and Prevotellaceae families and higher Enterobacteria and Enterococci (79).

CKD and ESRD influence considerably the composition of the intestinal flora and by extension its functions due to the multifaced occurring processes: impact of uremia, inflammation, and diet (79). However, it is noteworthy that dysbiosis in 
CKD patients may enhance uremic toxin concentrations that in their turn are involved in the progression of CKD (79). In developing countries, CKD is related to hypertension, diabetes, obesity, cardiovascular disease, glomerular and tubule interstitial, and aging (68). Moreover, exposure to factors such as toxins, antibiotics, drugs, iron intake, reduced dietary fiber intake, increased protein absorption, and finally slow intestinal transit could induce CKD and aggravate complications (68).

\section{Dialysis Patients}

When irreversible renal failure occurs, ESRD could be treated by hemodialysis or peritoneal dialysis in order to eliminate the toxic solutes or finally renal transplantation following availability of compatible donors. Dialysis permits elimination of a large number of toxins and waste solutes involved in the uremic syndrome. Of note is that hemodialysis or peritoneal dialysis may augment the permeability of the intestinal barrier in CKD patients and thus contributing to the translocation of endotoxins (79).

The gut microbiome of ESRD adult patients (Table 1) who underwent hemodialysis showed rise in Proteobacteria, Actinobacteria, and Firmicutes with preponderance of the subphylum Clostridia (79). Differences were observed in pediatric patients who underwent hemodialysis, as an increase in Bacteroidetes was found and reduction in Proteobacteria taxa (80). Besides, dialysis patients have low levels of SCFAs and butyrate due to the modification of the intestinal milieu and dysbiosis (81). Peritoneal dialysis patients' house differences in their gut microbiota, as a decrease in the taxa Firmicutes and Actinobacteria is observed.

A global study including more than half a million patients during 7 years in the United States states that the peritoneal dialysis was more frequent in rural areas (82). Surprisingly, the higher mortality rates were registered among Hispanic white patients living in remote rural places (82). However, people living in distant communities showed higher prevalence of ESRD to support a dialysis unit (82) and were supposed often to have a transplant (82). Likewise, when comparing dialysis patients in United Kingdom living in urban and rural areas, mortality rates were higher for people living in industrial areas (83). Yet, transplant rates were lower in Native Americans living in rural areas (82).

Overall, transplantation could impact on changes on the urinary and gut microbiota (84). Moreover, genetics, epigenetics, pharmacogenetics, hormonal status, and environmental factors (85) seem to impact and gut microbiota to be associated to worsen the situation in kidney allograft receivers (84). As stated, there is a reciprocal dialogue between kidney and gut, which is supposed to have a dynamic stress impacting on the microbiota. In this light, host immune responses initiate and could lead to infection and allograft rejection (84).

The importance of the microbiome is previously stated. Gut microbiota is able to trigger antigen-presenting cells (APCs) to initiate immune responses and alloimmune reactivity as observed in allogeneic bone marrow transplantation (HSCT) (86). When these allograft recipients were supposed to have gut decontamination, acute graft-vs.-host disease declined (87).
Research showed that posttransplant rejection is closely linked to the immunosuppression-driven dysbiosis (87). In this vein, overgrowth of opportunistic microorganisms and Escherichia coli is observed (88), as well as decreased diversity (89). Dysbiosis and bacterial diversity seem to be more pronounced when postoperative complications happen $(89,90)$, as dropping amounts of Firmicutes phylum and Lactobacillales order confluence together with enhancement of the Proteobacteria phylum population (91). Important changes in microbiota composition can be observed 1 month after transplantation linked basically to infectious events (87). Yet, enterococcal infections and diarrhea are associated with posttransplantation gut microbiota shifts (87).

Bacteroides, Streptococcaceae, Enterobacteriaceae, and Bifidobacteriaceae were found increased in cases of acute cell rejection, whereas Lactobacillaceae, Ruminococcaceae, Clostridiaceae, and Peptostreptococcaceae showed increased amounts in successful cases of transplantation (92). Interestingly, patients hosting Faecalibacterium prausnitzii in their microbiota seems to be in need of higher tacrolimus therapeutic doses (93), highlighting also the important role of the microbiota on drug metabolism as bacteria possess CYP P450 enzymes involved in drug metabolism (94).

\section{Autoimmune Disorders}

Gut dysbiosis may impact and promote autoimmune disorders such as inflammatory bowel disease (IBD), rheumatoid arthritis, type 1 diabetes, and multiple sclerosis. However, little information is obtained concerning the systematic lupus erythematosus (SLE), lupus nephritis $(46,64,95)$, and intestinal microbiota (49).

The increased numbers of Helicobacter pylori antigen found in renal biopsies argue that bacteria may keep an impact in membranous nephropathy and lupus nephritis (96).

Therefore, the gut microbiota amending polarization of the T-cell subsets and natural killer cells may have important immunomodulatory outcomes upon the autoimmune kidney disease (96). Immune system's impairment may also induce profound kidney injury (97).

Researchers stated that individuals with Crohn disease have a decrease in the abundance of Firmicutes and an increase in Bacteroidetes (98) (Table 1). Yet, they found that the enzyme urease shifts the microbiota in IBD rat models. Several intestinal bacteria possessing ureases convert urea to ammonia (99). Ammonia, a source of nitrogen, is utilized for protein synthesis in the host by hepatic metabolism. However, in individuals with liver damage, this conversion may be noxious, as high circulating ammonia levels result in hepatic encephalopathy (100).

The importance of the gut microbiota in the pathogenesis of renal impairment in lupus is stated (64). Scientists developing a lupus nephritis model in MRL/lpr mice observed considerable decrease of Lactobacillales in the gut microbiota and a leaky gut (101).

Engineering the gut microflora with bacteria having low urease activity in mice, it was demonstrated that ammonia levels were dropping, as well as neurobehavioral effects and mortality (102). 
In SLE patients, a decrease in the ratio Firmicutes/Bacteroidetes registered was studied by two different methodologies: 16S rRNA gene-based analysis and quantitative PCR, whereas Lachnospiraceae and Ruminococcaceae were associated with healthy individuals (103). Higher amounts of Bacteroidetes were found in SLE patients (103). Therefore, glycan degradation is overexpressed in the microbiota of SLE patients, presumably due to the higher population of Bacteroidetes (104). It is noteworthy that oxidative phosphorylation processes seem to be associated with SLE patients (105). T cells from patients with active lupus enhance mitochondrial oxidative phosphorylation, effecting in $\mathrm{O}_{2}$ generation that amends proteins (105).

The Goodpasture syndrome or anti-glomerular basement membrane disease (106) is a rare autoimmune disease that affects both the kidneys and the lungs. In kidney, the disease is due to circulating autoantibodies against the domain of the $\alpha 3$ chain of type IV collagen of glomerular and alveolar basement membranes. As a result, the patients develop rapidly glomerulonephritis with alveolar hemorrhage (106).

According to the hygiene hypothesis, early exposure to bacteria amends kidney damage and inflammation (107). In fact, germ-free mice models with ischemia-induced.

AKI showed extended renal damage compared to the control animals due to the Th1-type response as in the autoimmune disorders (107).

\section{Immunoglobulin a Nephropathy}

Immunoglobulin A nephropathy (IgAN) is a type of primary glomerular disease in adults (108). Prior studies have demonstrated an association between IgAN and dysregulation of the gut-associated lymphoid tissue (109). Gut microbiota shifting (Table 1) and dysbiosis may be the angular stone of the IgAN (60) as supported on a cross-sectional study in Chinese patients.

IgAN patients showed an increased abundance of Fusobacteria, whereas a decreased abundance of Synergistetes was stated (110). Hungatella, Escherichia-Shigella, and Eggerthella, genera having a pathogenic potential, were found in IgAN individuals, whereas the genus Escherichia-Shigella was linked pragmatically to the urinary albumin-to- creatinine ratio (uACR) but in a negative manner with glomerular filtration rate. Therefore, the genus rectale_group was found in low numbers in the IgAN patients associated negatively with the urinary uACR (110). Moreover, it was found that levels of urinary metabolites such as free amino acids and organic volatile compounds vary significantly between the progressor and non-progressor IgAN patients (111).

Chronic bacterial colonization and chronic infections of the upper respiratory tract may be involved in the development of IgA vasculitis and IgAN (112). Additionally, recent studies reported an association individual of IgA alimentary antigens, particularly gliadin and gut- associated hyperreactivity lymphoid tissue in IgAN patients (109).

\section{Diabetes}

Diabetes mellitus (DM) is characterized by metabolic disorders, high blood sugar concentrations, and frequently inflammation. $\mathrm{DM}$ is involved in CKD and ESRD.
DM type 2 (T2DM) is a metabolic disease characterized, among others, by inflammation as an outcome of visceral obesity, but when CKD or ESRD disease on dialysis is taking place, the inflammation status is multifaceted (113).

The interplay between increased intestinal permeability, high levels of LPS, and intestinal dysbiosis is known as endotoxemia and predisposes patients to T2DM, CKD, or ESRD on dialysis (113). During this chronic inflammation status of diabetes, there is decrease in beneficial bacteria numbers producing SCFAs and increase in proteolytic bacteria leading to uremic toxicity (113, 114).

By the aid of V4 16S rRNA pyrosequencing, it was reported that Bacteroidetes and Proteobacteria were higher in diabetic patients compared to the healthy group (114) (Table 1). In fact, the ratio between Firmicutes and Bacteroidetes decreases in human type 2 diabetes compared with controls (114), and the ratio Bacteroidetes to Firmicutes correlates positively with reduced glucose tolerance (114).

Diabetes type 1 in rats was reported to be associated with higher amounts of Bacteroides species (115), whereas Bacteroides-Prevotella species were related to a strong decrease of metabolic endotoxemia and inflammation in type 2 diabetes vs. class Clostridia and C. coccoides-E. rectale group (116).

It is noteworthy that the beneficial Bifidobacterium was associated with improved glucose tolerance and low inflammation (117). Surprisingly, Lactobacillus numbers were higher in diabetic persons compared to the non-diabetic. Lactobacillus have immunomodulating properties that may possibly be involved in the chronic inflammation processes in diabetic patients (118).

Diabetic kidney disease is a major cause of renal injury (119), occurring in $30 \%$ of the diabetic individuals. As stated, diabetes amends significant shifts in the dysbiotic microbiota and several metabolites (114). It was demonstrated that inhibition of the metabolite phenyl sulfate (PS) limits albuminuria in diabetic mice, whereas PS production is positively correlated with the progression of albuminuria (119).

In conclusion, there is evidence that the regulatory effect of the renal function is linked to specific bacteria of the microbiota that could modulate the renal function in diabetic nephropathy (120).

\section{Obesity}

Obesity is a risk factor for kidney disease as studies have shown that metabolic syndrome is also associated with the progression of kidney disease (121). Moreover, diabetes and glucose homeostasis are associated with obesity (122).

Unexpectedly, a negative correlation between ratios of Bacteroidetes to Firmicutes and body mass index (BMI) was found $(114,123)$ (Table 1 ) as it seems that obesity and diabetes are associated with distinct species of the gut microbiota. In obesity, dysbiosis is featured by an increase in the ratio Firmicutes/Bacteroidetes (124), and this correlates with studies reporting that weight increase is linked to a preponderance of Firmicutes against Bacteroidetes $(125,126)$. In line with the above, Prevotellaceae were also found at high levels in obese subjects, whereas Firmicutes were declined in patients with postgastric bypass (127) as they were supposed to have specific diet. 
Moreover, dropping in Clostridium species, C. coccoides group, and increasing in Bacteroides-Prevotella in case of weight loss were observed (124). In this regard, Firmicutes were associated with a low-fat/high-fiber diet (128). Yet, diet including whole grain increases the ratio Firmicutes/Bacteroidetes (129).

Overall, a confined intervariation in the diversity of fecal microbiota was evident in diabetic patients, reflecting diet differences, habits, environmental stressors, and other factors $(129,130)$.

It is stated that dysbiosis may be the etiology of the childhood obesity (126) as it is believed that increased Firmicutes/Bacteroidetes ratio in obese subjects could be a consequence of chronic dysbiosis and metabolic impairment (126).

Another aspect supported by researchers argues the interconnection of metabolic diseases with the presence of Gram-negative bacteria in the gut $(117,121)$. As known, LPSs situated in the outer membranes of gram-negative bacteria stimulate the inflammation processes and cause endotoxemia (131). Gut microbiota in diabetic subjects is characterized by Gram-negative bacteria of the phyla Bacteroidetes and Proteobacteria (113).

Therefore, microbial balance in the human gut seems to be associated with the pathophysiology of each disorder as distinct bacterial species may be involved and determine the progression and severity of CKD disease $(131,132)$.

\section{Hypertension}

As stated, there is an interconnection between gut microbiota, hypertension, and kidney disease (81). CKD is linked to hypertension and is featured by immune dysregulation and metabolic disorder due to the gut dysbiosis (133).

It is reported that the prevalence of hypertension increases gradually by increasing BMI from $\leq 5$ th $(2 \%)$ to $\geq 95$ th $(11 \%)$ (134). Moreover, higher fecal SCFA levels are associated with hypertension, gut dysbiosis, obesity, and cardiometabolic disease (84), which act to damage the kidney $(132,135,136)$.

The reciprocal crosstalk between hypertension and kidney disease seems to be linked to the presence of the olfactory receptor (Olfr78) in the renal juxtaglomerular apparatus, which participates in the secretion processes of renin in response to the intestinal SCFAs $(58,137)$. In this regard, it was demonstrated that when using antibiotics confining the gut microbiota potential, blood pressure is increasing in 0 lf $r 78$ knockout mice (58).

Shifting in microbiome profile was observed in patients with pulmonary hypertension (PAH) (138) compared to a reference cohort. Intestinal synthesis of arginine, proline, and ornithine was increased as well as TMA/TMAO and purine metabolism in $\mathrm{PAH}$ proving a shifting of the gut microbiota (139). TMA should be metabolized in TMAO accelerating atherosclerosis (139). Unlike in the reference cohort, butyrateand propionate-producing bacteria were shown in increasing numbers (139).

\section{Gut Kidney Microbiome Axis and Pregnancy-Related Complications}

Numerous studies support the involvement of human microbiota and microbial translocation in preeclampsia (PE) (140-143). A meta-analysis of epidemiologic studies indicated that any viral or bacterial infection relates to a higher risk of PE (two-fold) (91).

The placental microbiome exerts regulatory role in normal pregnancy (144). A beneficial interaction between active maternal immune system and human microbiome, gut, kidney, and placental, leads to pregnancy complications such as PE or fetal rejection $(145,146)$. The impact of microbial translocation $(34,147)$ into amniotic cavity and placenta $(148,149)$ is still unclear. It was proposed that bacterial translocation contributes immune cells, which could transport microorganisms by APCs (150).

Moreover, the bacterial translocation is carried by hematogenous dissemination (151). The placental microbiome of PE women often consists of Prevotella intermedia, Treponema denticola, Porphyromonas gingivalis, Actinobacillus actinomycetemcomitans, Fusobacterium nucleatum, Mycoplasma species, and Tannerella forsythensis $(152,153)$.

Dysbiosis leads to Immunological and metabolic shifts initiating PE pathophysiology $(154,155)$. The increased estrogen levels in pregnant women lead to increased deposits of glycogen in the vaginal epithelium, which provides a better substrate for the growth of microorganisms, consequently bacterial translocation $(154,155)$. Moreover, bacterial contamination of placenta could impact upon endothelial permeability (155). As stated, F. nucleatum usually presented in oral cavity could spread hematogenous to the placenta and alter the vascular endothelium permeability (156). Yet, high permeability allows colonization by pathogenic organisms, such as E. coli (156). The increase of placental bacterial load promotes neutrophil migration, activation, and formation of neutrophil extracellular traps (NETs) (157). Recent data indicated that NETs stimulate the coagulation pathways through elevated tissue factor expression, red blood cell adhesion, and platelet activation $(152,158)$. Activation of the coagulation pathways is implicated in pathogenesis of PE and leads to multiorgan damage (159).

Furthermore, gut microbiome dysbiosis leads to gestational diabetes, which is an independent risk factor for PE (160, 161). In addition, it was shown that bacterial burden was correlated to other risk factors of PE, such as hypertension and proteinuria (162).

\section{Therapeutic Approaches}

Restoring the balance of the intestinal microbiota seems to be the cornerstone for improving gut dysbiosis that leads to immunological dysfunction, inflammation, and kidney disease.

Diet is important in the shaping of the intestinal microbiota (163-165). In patients with severe CKD, strict dietary restrictions are imposed in order to prevent hyperkalemia and oxalate surcharge. Consequently, these dietary restrictions could influence microbiota functions (69). Additionally, those patients are taking systematically phosphate-binding agents in order to limit phosphate absorption (69). Antibiotic intake to treat dysbiosis modifies heavily the intestinal microbiota and its 
functions $(166,167)$. It is of note that also a high-salt diet modifies the intestinal microbiota and contributes to the CKD progression (168). Therefore, decreased levels of Lactobacillus were found under high-salt diet (168) in tandem with low populations of Th17 lymphocytes. Lactobacillus intake may restore Th17 lymphocyte levels (168).

In line with the above, we stated several therapeutic approaches that reduce the uremic toxins (169) and improve the microbiota. Probiotics, prebiotics, and synbiotics were given as adjuvant therapy as the point to the balance of the intestinal microbiota $(166,169)$. Probiotics not only improve the levels of uremic toxins in blood but also restore the gut microbial balance (169). However, it is of note that their effect is probiotic strain dependent (166) based on the expression of functional biomarkers. Probiotics enhancement of epithelial intestinal integrity impedes pathogen entry and adhesion into the epithelial cells (170).

In this regard, probiotics create usually a mucus barrier or even produce soluble proteins to protect the host $(170,171)$. Antimicrobial peptides are produced from several probiotics expulsing pathogenic bacteria (172) or act as signaling peptides (173). Moreover, several Lactobacillus are able to turn the gut $\mathrm{pH}$ in acid as they produce acids (172). Other Lactobacillus could interpose on the pathogens gene and reduce their aggressive progression (174) for example Lactobacillus acidophilus against the enterohemorrhagic E. coli O157:H7 (175).

Engineering of the gut microbiota with probiotics showed glucose homeostasis and reduced inflammation and hepatic steatosis as probiotics could modulate the bile acid and SCFA profiles and LPS production (176-178). Overall probiotics are live bacteria that participate actively in the gut metabolism (179). Last but not least is the effect of probiotics upon immunity and inflammation (166). Probiotics enhance both innate and adaptive immunity and increase production of IgA. Cytokine increase in the serum is observed due to their immunomodulatory response (166).

However, some controversial effects were shown in patients who underwent dialysis receiving probiotics as proinflammatory cytokines and endotoxin levels were found low (180). We suppose that this may be due to the overhydrated state of the dialysis patients that amends the real presented levels (180).

Prebiotics are non-digestible fibers inducing the growth and activity of intestinal bacteria for the balance of the gut microbiota. They are used as food supplements. Prebiotics produce SCFAs, improve the intestinal barrier integrity and function, regulate the inflammation and the immune system dysfunction, and finally modulate the glucose and lipid metabolism (179). Prebiotics given to CKD adult patients as well as to pediatric patients with ESRD showed decrease in serum urea nitrogen concentration and improved the clinical status (80). In this line, a study in patients who underwent hemodialysis showed reduced plasma levels of the uremic toxins when patients were given dietary fibers for at least 6 weeks (180).

As known, synbiotics combine both probiotics and prebiotics possessing combined activity. Synbiotics were given to multiple renal dysfunctions, and they showed a lowering of the urine toxins, which confluence with CKD improvement and delay progression of CKD (181). Improvement of the microbiota was also observed as higher Bifidobacterium and lower Ruminococcaceae populations were found (181).

We discussed the importance of SCFAs previously. Alternative therapy with SCFAs such as butyrate, acetate, and propionate improves renal function as they are able to lower inflammation, infiltrating immune cells, and apoptotic cells in kidneys (182).

Fecal microbiota transplantation (FMT) was used as an interventional method in patients with recurrent diarrhea when antibiotics fail (183). There is a debate between scientists on its application mainly based in ethical issues and safety. While safety is thoroughly checked through carefully selected donors and strict microbiological control techniques, international consensus is not effective, yet because of the ethical, logistical, and technical issues $(183,184)$. Clostridium difficile infectious diarrhea was alleviated successfully following FMT (185). There are few published data in renal patients treated with FMT. An interesting case is the successful treatment of diarrhea induced by tyrosine kinase inhibitors in patients with metastatic renal cell carcinoma (186).

Scientists showed the effect of an adsorbent therapy (AST120) on dialysis patients with CKD (187). AST-120 is an orally given carbon adsorbent that adsorbs indole and indoxyl sulfate (IS) in CKD patients (188). Moreover, AST-120 seems to extend the time to the initiation of dialysis (189) as it improves the clinical image of the patient. The attenuation of the chronic renal failure by reducing proteinuria and oxidative stress was observed (189), as improvement of the tubular injury was effective. However, most studies on AST-120 are originating from Japan, and little knowledge is gained from international scientist community.

Last but not least, we state here the modulation of the intestinal microbiota following kidney transplantation $(183,190)$.

\section{CONCLUSION}

In the present review, we aimed to shed light in the crosstalk between human gut microbiome and kidney disease. Intestinal dysbiosis leads to microbiota shifts including unbalance of the normal intestinal microbiota, metabolic disarrangements, inflammation, immunosuppression, and accumulation of uremic toxins, which lead to the gradual kidney failure.

The hygiene hypothesis seems to be effective since early intestinal colonization especially by beneficial bacteria in newborns predispose to a better health status and offer subsequent protection from many different types of diseases. New therapeutic strategies for restoration of the imbalanced microbiota involve probiotics, prebiotics, synbiotics, and adsorbent therapy but also the questionable fecal transplantation therapy.

Microbial-modulating approaches seem to be the gold standard for prophylaxis and therapy especially after the failure of multiple courses of antibiotics given also their low cost. 
However, the implementation of such therapies must be applied with attention following strict selection criteria, efficacy, and safety issues.

We highlight here the need to proceed to more clinical investigations in large samples of renal patients, as well as basic research for enriching our knowledge on the kidney-gut axis and undertake effective and safe therapeutic approaches.

\section{REFERENCES}

1. Walker WA. Initial intestinal colonization in the human infant and immune homeostasis. Ann Nutr Metab. (2013) 63(S2):8-15. doi: 10.1159/000354907

2. Bezirtzoglou E, Tsiotsias A, Welling GW. Microbiota profile in feces of breast- and formula-fed newborns by using fluorescence in situ hybridization (FISH). Anaerobe. (2011) 17:478-82. doi: 10.1016/j.anaerobe.2011.03.009

3. Bezirtzoglou E, Stavropoulou E. Immunology and probiotic impact of the newborn and young children intestinal microflora. Anaerobe. (2001)17:36974. doi: 10.1016/j.anaerobe.2011.03.010

4. Bezirtzoglou E, Romond C. Effect of the feeding practices on the establishment of bacterial interactions in the intestine of the newborn delivered by cesarean section. J Perinat Med. (1990) 18:139-43. doi: 10.1515/jpme.1990.18.2.139

5. Konstandi M, Voidarou C, Papadaki A, Tsiotsias A, Kotsovolou O, Evangelou E, Bezirtzoglou E. Stress modifies the vaginal flora in cyclic female rats. Micr Ecol Health Dis. (2009) 18:161-9. doi: 10.1080/08910600601072464

6. Johnson JS, Spakowicz DJ, Hong B-Y, Petersen LM, Demkowicz P, Chen L, et al. Evaluation of $16 \mathrm{~S}$ rRNA gene sequencing for species and strain-level microbiome analysis. Nat Commun. (2019) 10:5029. doi: 10.1038/s41467-019-13036-1

7. Al Khodor S, Shatat IF. Gut microbiome and kidney disease: a bidirectional relationship. Pediatr Nephrol. (2017) 32:921-31. doi: 10.1007/s00467-016-3392-7

8. Bezirtzoglou E. The intestinal microflora during the first weeks of life. Anaerobe. (1997)3:173-77. doi: 10.1006/anae.1997.0102

9. Adlerberth I, Wold AE. Establishment of the gut microbiota in Western infants. Acta Paediatr. (2009) 98: 229-38. doi: 10.1111/j.1651-2227.2008.01060.x

10. Cani PD. Human gut microbiome: hopes, threats and promises. Gut. (2018) 67:1716-25. doi: 10.1136/gutjnl-2018-316723

11. Sprockett D, Fukami T, Relman DA. Role of priority effects in the early-life assembly of the gut microbiota. Nat Rev Gastroenterol Hepatol. (2018)15:197-05. doi: 10.1038/nrgastro.2017.173

12. Martin-Gallausiaux C, Marinelli L, Blottière H, Larraufie P, Lapaque N. SCFA: mechanisms and functional importance in the gut. Proc Nutr Soc. (2020) 1-13. doi: 10.1017/S0029665120006916

13. Louis P, Flint H. Formation of propionate and butyrate by the human colonic microbiota. Env Microbiol. (2017) 19: 29-1. doi: 10.1111/1462-2920.13589

14. Tan J, Mckenzie C, Potamitis M, Thorburn AN, Mackay Cr, Macia L. The Role of short-chain fatty acids in health and disease. Adv Immunol. (2014) 121:91-119. doi: 10.1016/B978-0-12-800100-4.00003-9

15. Angueira AR, Brodsky M, Durai V,. LoweJr WL. Short chain fatty acids and their receptors: new metabolic targets. Transl Res. (2013) 161:131-40. doi: $10.1016 /$ j.trsl.2012.10.007

16. Schilderink R, Verseijden C, de Jonge WJ. Dietary inhibitors of histone deacetylases in intestinal immunity and homeostasis. Front. Immunol. (2013) 4:226. doi: 10.3389/fimmu.2013.00226

17. Prescott S. History of Medicine: Origin of the term microbiome and why it matters. Hum Microb J. (2017) 4:24-5. doi: 10.1016/j.humic.2017.05.004

18. Zhu B, Wang X, Li L. Human gut microbiome: the second genome of human body. Protein Cell. (2010) 1:718-25. doi: 10.1007/s13238-010-0093-Z

19. Human Microbiome Project - Home. NIH Common Fund. (2020). Available online at: https://commonfund.nih.gov/hmp/ (accessed August 20, 2020).

20. METAHIT (Metagenomics of the Human Intestinal Tract). Final Report Summary METAHIT FP7 CORDIS European Commission. (2020). Available

\section{AUTHOR CONTRIBUTIONS}

ES: conceptualization, writing, and editing. TK and KK: formal analysis and writing. GR: writing and investigation. CV: resources and writing. CT: writing and editing. EB: supervision, original draft preparation, and editing. All authors contributed to the article and approved the submitted version.

online at: https://cordis.europa.eu/project/id/201052/reporting (accessed August 22, 2020).

21. Arumugam M, Raes J, Pelletier E, Le Paslier D, Yamada T, Mende DR, et al. Enterotypes of the human gut microbiome. Nature. (2011) 12:473:174-80. doi: 10.1038/nature09944

22. Wu GD, Chen J, Hoffmann C, Bittinger K, Chen Y-Y, Keilbaugh SA, et al. Linking long-term dietary patterns with gut microbial enterotypes. Science. (2011) 334:105-8. doi: 10.1126/science.1208344

23. Méndez-Salazar EO, Ortiz-López MG, Granados-Silvestre MÁ, Palacios-González B and Menjivar M. Altered gut microbiota and compositional changes in Firmicutes and Proteobacteria in Mexican undernourished and obese children. Front Microbiol. (2018) 9:2494. doi: $10.3389 /$ fmicb.2018.02494

24. Belizário JE, Faintuch J, Garay-Malpartida M. Gut microbiome dysbiosis and immunometabolism: new frontiers for treatment of metabolic diseases. Mediators Inflamm. (2018) 2018:2037838. doi: 10.1155/2018/2037838

25. Brown J, Robusto B, Morel L. Intestinal dysbiosis and tryptophan metabolism in autoimmunity. Front Immunol. (2020) 11:1741. doi: 10.3389/fimmu.2020.01741

26. Aragón IM, Herrera-Imbroda B, Queipo-Ortuño MI, Castillo E, Del Moral JS-G, Gómez-Millán J, et al. The urinary tract microbiome in health and disease. Eur Urol Foc. (2018) 4:128-38. doi: 10.1016/j.euf.2016.11.001

27. Whiteside SA, Razvi H, Dave S, Reid G, Burton JP. The microbiome of the urinary tract-a role beyond infection. Nature Rev Urol. (2015) 12:81-90. doi: 10.1038/nrurol.2014.361

28. Alfano M, Canducci F, Nebuloni M, Clementi M, Montorsi F, Salonia A. The interplay of extracellular matrix and microbiome in urothelial bladder cancer. Nat Rev Urol. (2016) 13:77-90. doi: 10.1038/nrurol.2015.292

29. Lewis DA, Brown R, Williams J, White P, Jacobson SK, Marchesi J, et al. The human urinary microbiome; bacterial DNA in voided urine of asymptomatic adults. Front Cell Infect Microbiol. (2013)3:41. doi: 10.3389/fcimb.2013. 00041

30. Pearce MM, Hilt EE, Rosenfeld AB, Zilliox MJ, Thomas-White K, Fok $\mathrm{C}$, et al. The female urinary microbiome: a comparison of women with and without urgency urinary incontinence. mBio. (2014) 5:e01283-14. doi: 10.1128/mBio.01283-14

31. Kliman HJ. Comment on "The placenta harbors a unique microbiome." Sci Transl Med. (2014) 6:254le4. doi: 10.1126/scitranslmed. 3009864

32. Govender Y, Gabriel I, Minassian V, Fichorova R. The current evidence on the association between the urinary microbiome and urinary incontinence in women. Front Cell Infect Microbiol. (2019) 9:133. doi: $10.3389 /$ fcimb.2019.00133

33. Kramer H, Kuffel G, Thomas-White K, Wolfe AJ, Vellanki K, Leehey DJ, et al. Diversity of the midstream urine microbiome in adults with chronic kidney disease. Int Urol Nephrol. (2018) 50:1123-30. doi: 10.1007/s11255-018-1860-7

34. Mielcarek C, Romond PC, Romond MB, Bezirtzoglou E. Modulation of bacterial translocation in mice mediated through lactose and human milk oligosaccharides. Anaerobe. (2011) 17:361-6. doi: 10.1016/j.anaerobe.2011.09.002

35. Berg RD. Bacterial translocation from the gastrointestinal tract. Trends Microb. (1995) 473:11-30. doi: 10.1007/978-1-4615-4143-1_2

36. Gebbers J-O, Laissue J-A. Bacterial translocation in the normal human appendix parallels the development of the local immune system. Ann New York Acad Sci. (2004) 1029:337-43. doi: 10.1196/annals.1309.015 
37. Hobby GP, Karaduta O, Dusio GF, Singh M, Zybailov BL, Arthur JM. Chronic kidney disease and the gut microbiome. Am J Physiol Renal Physiol. (2019) 316:F1211-7. doi: 10.1152/ajprenal.00298.2018

38. Maynard CL, Elson CO, Hatton RD, Weaver CT. Reciprocal interactions of the intestinal microbiota and immune system. Nature. (2012) 489:231-41. doi: 10.1038/nature11551

39. Dhana E, Ludwig-Portugall I, Kurts C. Role of immune cells in crystal-induced kidney fibrosis. Matrix Biol. (2018) 68-69:280-92. doi: 10.1016/j.matbio.2017.11.013

40. Guiteras R, Flaquer M, Cruzado JM. Macrophage in chronic kidney disease. Clin Kidney J. (2016) 9:765-71. doi: 10.1093/ckj/sfw096

41. Tang PC, Zhang YY, Chan MK, Lam WW, Chung JY, Kang W, et al. The emerging role of innate immunity in chronic kidney diseases. Int J Mol Sci. (2020) 21:4018. doi: 10.3390/ijms21114018

42. Leemans JC, Kors L, Anders HJ, Florquin S. Pattern recognition receptors and the inflammasome in kidney disease. Nature Rev Nephrol. (2014) 10:398414. doi: 10.1038/nrneph.2014.91

43. Eppensteiner J, Kwun J, Scheuermann U, Barbas A, Limkakeng AT, Kuchibhatla M, et al. Damage- and pathogen-associated molecular patterns play differential roles in late mortality after critical illness. JCI Insight. (2019) 4:e127925. doi: 10.1172/jci.insight. 127925

44. De Heer E, Peters DJM. Innate immunity as a driving force in renal disease. Kidney Intern. (2008) 73:7-8. doi: 10.1038/sj.ki.5002658

45. Cowan KJ, Storey KB. Mitogen-activated protein kinases: new signaling pathways functioning in cellular responses to environmental stress. $J$ Exp Biol. (2003) 206:1107-115. doi: 10.1242/jeb.00220

46. Shi Y, Kaliyaperumal A, Lu L, Southwood S, Sette A, Michaels MA, Datta SK. Promiscuous presentation and recognition of nucleosomal autoepitopes in lupus: role of autoimmune T cell receptor $\alpha$ chain. J Exp Med. (1998) 187:367-78. doi: 10.1084/jem.187.3.367

47. Hong S, Healy H, Kassianos AJ. The emerging role of renal tubular epithelial cells in the immunological pathophysiology of lupus nephritis. Front Immunol. (2020) 11:578952. doi: 10.3389/fimmu.2020.578952

48. De Haij S, Woltman Am, Trouw LA, Kroczek RA, Daha MR, Van Kooten C. Renal tubular epithelial cells modulate T-cell responses via ICOS-L and B7-H1. Cell Biol Immunol Pathol. (2005) 68:2091-102. doi: 10.1111/j.1523-1755.2005.00665.x

49. Gong J, Noel S, Pluznick JL, Hamad ARA, Rabb H. Gut microbiotakidney cross-talk in acute kidney injury. Semin Nephrol. (2019) 39:107-16. doi: 10.1016/j.semnephrol.2018.10.009

50. Alissafi T, Banos A, Boon L, Verginis P. Tregs restrain dendritic cell autophagy to ameliorate autoimmunity. J Clin Inv. (2017) 127:2789-804. doi: 10.1172/JCI92079

51. Alikhan MA, Huynh M, Kitching AR, Ooi JD. Regulatory T cells in renal disease. Clin Transl Immunol. (2018) 7:e1004. doi: 10.1002/cti2. 1004

52. Mitsdoerffer M, Lee $\mathrm{Y}$, Jäger A, Kim HJ, Korn T, Kolls JK, et al. Proinflammatory T helper type 17 cells are effective B-cell helpers. PNAS USA. (2010) 107:14292-7. doi: 10.1073/pnas.1009234107 Epub 2010 Jul 26

53. Zheng L, Sinniah R, Hsu SI. Pathogenic role of NF-kappa B activation in tubulointerstitial inflammatory lesions in human lupus nephritis. $J$ Histochem Cytochem. (2008) 56:517-29. doi: 10.1369/jhc.7A7368.2008

54. Hazanberg MD, Spits H. Human innate lymphoid cells. Blood. (2014) 124:700-9. doi: 10.1182/blood-2013-11-427781

55. Li S, Bostick JW, Zhou L. Regulation of innate lymphoid cells by aryl hydrocarbon receptor. Front Immunol. (2018) 8:1909. doi: 10.3389/fimmu.2017.01909

56. Krebs CF, Paust HJ, Krohn S, Koyro T, Brix SR, Riedel J-H, et al. Autoimmune renal disease Is exacerbated by S1P-receptor-1-dependent intestinal Th17 cell migration to the kidney. Immunity. (2016) 45:1078-92. doi: 10.1016/j.immuni.2016.10.020

57. Luu M, Monning $\mathrm{H}$, Visekruna A. Exploring the molecular mechanisms underlying the protective effects of microbial SCFAs on intestinal tolerance and food allergy. Front Immunol. (2020) 11:1225. doi: 10.3389/fimmu.2020.01225

58. Pluznick JL, Protzko RJ, Gevorgyan H, Peterlin Z, Sipos A, Han J, et al. Olfactory receptor responding to gut microbiota-derived signals plays a role in renin secretion and bloodpressure regulation. PNAS USA. (2013) 110:4410-15. doi: 10.1073/pnas.1215927110

59. Al-Harbi NO, Nadeem A, Ahmad SF, Alotaibi MR, AlAsmari AF, Alanazi WA, et al. Short chain fatty acid, acetate ameliorates sepsis-induced acute kidney injury by inhibition of NADPH oxidase signaling in T cells. Int Immunopharmacol. (2018) 58:24-31. doi: 10.1016/j.intimp.2018.02.023

60. Mielenz M, Kuhla B, Hammon HM. Abundance of adiponectin system and G-protein coupled receptor GPR109A mRNA in adipose tissue and liver of F2 offspring cows of Charolais x German Holstein crosses that differ in body fat accumulation. J Dairy Sci. (2013) 96:278-89. doi: 10.3168/jds.2012-5816

61. Andrade-Oliveira V, Amano MT, Correa-Costa M, Castoldi A, Felizardo RJF, de Almeida DC, et al. Gut bacteria products prevent AKI induced by ischemia-reperfusion. JASN. (2015) 26:1877-88. doi: 10.1681/ASN.2014030288

62. Durr UHN, Sudheendra US, Ramamoorthy A. LL-37, the only human member of the cathelicidin family of antimicrobial peptides. BBA-Biomem. (2006) 1758:1408-25. doi: 10.1016/j.bbamem.2006.03.030

63. Zong $\mathrm{X}$, $\mathrm{Fu} \mathrm{J}$, $\mathrm{Xu} \mathrm{B}$, Wang $\mathrm{Y}$, Jin $\mathrm{M}$. Interplay between gut microbiota and antimicrobial peptides. Animal Nutr. (2020) 6:389-96. doi: 10.1016/j.aninu.2020.09.002

64. Mu Q, Zhang H, Liao X, Lin K, Liu H, Edwards MR, et al. Control of lupus nephritis by changes of gut microbiota. Microbiome. (2017) 5:73. doi: 10.1186/s40168-017-0300-8

65. Meyer TW, Hostetter TH. Uremia. N Engl J Med. (2007) 357:1316-25. doi: 10.1056/NEJMra071313

66. Stanford J, Charlton K, Stefoska-Needham A, Ibrahim R, Lambert K. The gut microbiota profile of adults with kidney disease and kidney stones: a systematic review of the literature. BMC Nephrol. (2020) 21:215. doi: 10.1186/s12882-020-01805-w

67. Evenepoel P, Poesen R, Meijers B. The gut-kidney axis. Pediatr Nephrol. (2017) 32:2005-14. doi: 10.1007/s00467-016-3527-x

68. Pan W, Kang Y. Gut microbiota and chronic kidney disease: implications for novel mechanistic insights and therapeutic strategies. Int Urol Nephrol. (2018) 50:289-99. doi: 10.1007/s11255-017-1689-5

69. Vaziri ND, Wong J, Pahl M, Piceno YM, Yuan J, De Santi TZ, et al. Chronic kidney disease alters intestinal microbial flora. Kidney Int. (2013) 83:308-15. doi: 10.1038/ki.2012.345

70. Anderson JM, van Itallie CM. Physiology and function of the tight junction. Cold Spring Harb Perspect Biol. (2009) 1:a002584. doi: 10.1101/cshperspect.a002584

71. Poesen R, Meijers B, Evenepoel P. The colon: an overlooked site for therapeutics in dialysis patients. Sem Dialysis. (2013) 26:323-32. doi: $10.1111 /$ sdi.12082

72. Guo S, Al-Sadi R, Said HM, Ma TY. Lipopolysaccharide causes an increase in intestinal tight junction permeability in vitro and in vivo by inducing enterocyte membrane expression and localization of TLR-4 and CD14. Am J Pathol. (2013) 182:375-87. doi: 10.1016/j.ajpath.2012.10.014

73. Wu T-K, Wei C-W, Pan Y-R, Hsu R-J, Wu C-Y, Yu Y-L. The uremic toxin p-cresyl sulfate induces proliferation and migration of clear cell renal cell carcinoma via microRNA- 21/ HIF-1 $\alpha$ axis signals. Sci Rep. (2019) 9:3207. doi: 10.1038/s41598-019-39646-9

74. Kim Y-H, Kwak K-A, Gil H-W, Song H-Y, Hong S-Y. Indoxyl sulfate promotes apoptosis in cultured osteoblast cells. BMC Pharmacol Toxicol. (2013)1:60-6. doi: 10.1186/2050-6511-14-60

75. Koppe L, Mafra D, Fouque D. Probiotics and chronic kidney disease. Kidney Int. (2015) 88:958-66. doi: 10.1038/ki.2015.255

76. Richards JL, Yap YA, McLeod KH, Mackay CR, Mariño E. Dietary metabolites and the gut microbiota: an alternative approach to control inflammatory and autoimmune diseases. Clin Transl Immunol. (2016) 5:e82. doi: 10.1038/cti.2016.29

77. Ranganathan N, Ranganathan P, Friedman EA, Joseph A, Delano B, Goldfarb DS, et al. Pilot study of probiotic dietary supplementation for promoting healthy kidney function in patients with chronic kidney disease. Adv The. (2010) 27:634-47. doi: 10.1007/s12325-010-0059-9

78. Fukuuchi F, Hida M, Aiba Y, Koga Y, Endoh M, Kurokawa K, et al. Intestinal bacteria-derived putrefactants in chronic renal failure. Clin Exp Nephrol. (2002) 6:99-4. doi: 10.1007/s101570200016 
79. Nalewajska M, Przybycinski J, Marchelek-Mysliwiec M, Dziedziejko $\mathrm{V}$, Ciechanowski K. Gut microbiota in chronic kidney disease. Adv Microbiol. (2019)56:237-45. doi: 10.21307/PM-2019. 58.3.237

80. Crespo-Salgado J, Vehaskari VM, Stewart T, Ferris M, Zhang Q, Wang G, et al. Intestinal microbiota in pediatric patients with end stage renal disease: a Midwest Pediatric Nephrology Consortium study. Microbiome. (2016) 4:50. doi: 10.1186/s40168-016-0195-9

81. Wong J, Piceno YM, DeSantis TZ, Pahl M, Andersen GL, Vaziri ND. Expansion of urease- and uricase-containing, indole- and p-cresolforming and contraction of short- chain fatty acid-producing intestinal microbiota in ESRD. Am J Nephrol. (2014). 39:230-7.doi: 10.1159/0003 60010

82. O’Hare AM, Johansen KL, Rodriguez RA. Dialysis and kidney transplantation among patients living in rural areas of the United States. Kidney Int. (2006) 69:343-49. doi: 10.1038/sj.ki.5000044

83. O’Riordan E, Lambe D, O’Donoghue DJ, New J, Foley RN. Variation in dialysis patient mortality by health authority. Q J Med. (2003) 96:739-45. doi: 10.1093/qjmed/hcg127

84. Ardalan M, ZununiVahed S.Gut microbiota and renal transplant outcome. Biomed Pharmacother. (2017) 90:229-36. doi: 10.1016/j.biopha.2017.02.114

85. Zunini Vahed S, Ardalan M, Samadi N, Omidi Y. Pharmacogenetics and drug-induced nephrotioxicity in renal transplant recipients. Bioimpacts. (2015) 5:45-54. doi: 10.15171/bi.2015.12

86. Vossen JM, Guiot HF, Lankester AC, Vossen ACTM, Bredius RGM, Wolterbeek $\mathrm{R}$, et al. Complete suppression of the gut microbiome prevents acute graft-versus-host disease following allogeneic bone marrow transplantation. PLoS ONE. (2014) 9:e105706. doi: 10.1371/journal.pone.0105706

87. Lee JR, Muthukumar T, Dadhania D, Toussaint NC, Ling L, Pamer E, et al. Gut microbial community structure and complications after kidney transplantation: a pilot study. Transplantation. (2014) 98:697-705. doi: 10.1097/TP.0000000000000370

88. Tourret J, Willing BP, Dion S, MacPherson J, Denamur E, Finlay BB. Immunosuppressive treatment alters secretion of ileal antimicrobial peptides and gut microbiota, and favors subsequent colonization by uropathogenic Escherichia coli.Transplantation. (2017) 101:74-82. doi: 10.1097/TP.0000000000001492

89. $\mathrm{Lu} \mathrm{H}, \mathrm{He} J$, Wu Z, Xu W, Zhang $\mathrm{H}$, Ye $\mathrm{P}$, etal. Assessment of microbiome variation during the perioperative period in liver transplant patients: a retrospective analysis. Microb Ecol. (2013) 65:781-91. doi: 10.1007/s00248-013-0211-6

90. Xie Y, Luo Z, Li Z, Deng M, Liu H, Zhu B, et al. Structural shifts of fecal microbial communities in rats with acute rejection after liver transplantation. Microb Ecol. (2012) 64:546-54. doi: 10.1007/s00248-012-0030-1

91. Oh PL, Martinez I, Sun Y, Walter J, Peterson DA, Mercer DF. Characterization of the ileal microbiota in rejecting and non-rejecting recipients of small bowel transplants Am J Transplant. (2012) 12:753-62. doi: 10.1111/j.1600-6143.2011.03860.x

92. Xiao J, Peng Z, Liao Y, Sun H, Chen W, Chen X, et al. Organ transplantation and gut microbiota: current reviews and future challenges. Am J Transl Res. (2018) 10:3330-44.

93. Lee JR, Muthukumar T, Dadhania D, Taur Y, Jenq RR, Toussaint NC, et al. Gut microbiota and tacrolimus dosing in kidney transplantation. PLoS ONE. (2015)10:e0122399. doi: 10.1371/journal.pone.0122399

94. Bezirtzoglou EE. Intestinal cytochromes $\mathrm{P} 450$ regulating the intestinal microbiota and its probiotic profile. Microb Ecol Health Dis. (2012) 23:1-9. doi: 10.3402/mehd.v23i0.18370

95. Lightfoot YL, Blanco LP, Kaplan MJ. Metabolic abnormalities and oxidative stress in lupus: Curr Opin Rheumatol. (2017) 29:442-9. doi: 10.1097/bor.0000000000000413

96. Wijarnpreecha K, Thongprayoon C, Nissaisorakarn P, Jaruvongvanich V, Nakkala K, Rajapakse R, et al. Association of Helicobacter pylori with chronic kidney diseases: a meta-analysis. Dig Dis Sci. (2017) 62:2045-52. doi: 10.1007/s10620-017-4516-Z

97. Macpherson AJ, Harris NL. Interactions between commensal intestinal bacteria and the immune system. Nature Rev Immunol. (2004) 4:478-85. doi: $10.1038 /$ nri1373
98. Wu GD. Changing Gut Bacteria in Crohn's Disease. National Institutes of Health (NIH) 2017. Available online at: https://www.nih.gov/news-events/ nih- research-matters/changing-gut-bacteria-crohns-disease.

99. Nunes-Alves C. Modifying the gut to treat liver diseases. Nature Rev Microb. (2015) 13:458-58. doi: 10.1038/nrmicro3531

100. Al-Osaimi AMS. Hepatic encephalopathy. Saudi J Gastrenterol. (2012) 18:301-6. doi: 10.4103/1319-3767.101123

101. Gunnia UB, Amenta PS, Seibold JR, Thomas TJ. Successful treatment of lupus nephritis in MRL-lprllpr mice by inhibiting ornithine decarboxylase. Kidney Int. (1991) 39:882--90.

102. Dosoky NS, May-Zhang LS, Davies SS. Engineering the gut microbiota to treat chronic diseases. Appl Microbiol Biotechnol. (2020) 104:7657-71. doi: 10.1007/s00253-020-10771-0

103. Hevia A, Milani C, López P, Cuervo A, Arboleya S, Duranti S, et al. Intestinal dysbiosis associated with systemic lupus erythematosus. mBio. (2014) 5:e01548-14. doi: 10.1128/mBio.01548-14

104. $\mathrm{Mu} \mathrm{Q}$, Zhang $\mathrm{H}$, Luo XM. Another autoimmune disorder influenced by microbes and diet? Front Immunol. (2015) 6:608. doi: 10.3389/fimmu.2015.00608

105. Namas R, Renauer P, Ognenovski M, Tsou P-S, Sawalha AH. Histone H2AX phosphorylation as a measure of DNA double-strand breaks and a marker of environmental stress and disease activity in lupus. Lupus Sci Med. (2016) 3:e000148.

106. Henderson SR, Salama AD. Diagnostic and management challenges in Goodpasture's (anti-glomerular basement membrane) disease. Nephrol Dial Transplant. (2018) 33:196-02. doi: 10.1093/ndt/gfx057

107. Jang HR, Gandolfo MT, Ko GJ, Satpute S, Racusen L, Rabb H. Early exposure to germs modifies kidney damage and inflammation after experimental ischemia- reperfusion injury. Am J Physiol Renal Physiol. (2009) 297:F14571465. doi: 10.1152/ajprenal.90769.2008

108. Wyatt RJ, Julian BA. IgA nephropathy. N Engl J Med. (2013) 368:2402 14.doi: 10.1056/NEJMra1206793

109. Coppo R. The Gut-Renal Connection in IgA Nephropathy. Semin Nephrol. (2018) 38:504-12. doi: 10.1016/j.semnephrol.2018.05.020

110. Hu X, Du J, Xie Y, Huang Q, Xiao Y, Chen J, et al. Fecal microbiota characteristics of Chinese patients with primary IgA nephropathy: a cross-sectional study. BMC Nephrol. (2020) 13:21, 97. doi: 10.1186/s12882-020-01741-9

111. De Angelis M, Montemurno E, Piccolo M, Vannini L, Lauriero G, Maranzano V, et al. Microbiota and metabolome associated with immunoglobulin A nephropathy (IgAN). PLoS ONE. (2014) 9:e99006. doi: 10.1371/journal.pone.0099006

112. Jennette JC, Stone JR. IgA vasculitis - an overview. In: Willis M, Homeister J, Stone J, editors. Cellular and Molecular Pathology of Cardiovascular Disease. 1st ed. Boston, MA: Academic Press, eBook (2014).

113. Sabatino A, Regolisti G, Cosola C, Gesualdo L, Fiaccadori E. Intestinal microbiota in type 2 diabetes and chronic kidney disease. Curr Diab Rep. (2017) 17:16. doi: 10.1007/s11892-017-0841-z

114. Larsen N, Vogensen FK, van den Berg FW, Nielsen DS, Andreasen AS, Pedersen BK, et al. Gut microbiota in human adults with type 2 diabetes differs from non-diabetic adults. PLoS ONE. (2010) 5:e9085. doi: 10.1371/journal.pone.0009085

115. Brugman S, Klatter FA, Visser JTJ, Wildeboer-Veloo ACM, Harmsen HJM, Rozing J, et al. Antibiotic treatment partially protects against type 1 diabetes in the Bio-Breeding diabetes-prone rat. Is the gut flora involved in the development of type 1 diabetes? Diabetologia. (2006) 49:2105-8. doi: 10.1007/s00125-006-0334-0

116. Cani PD, Possemiers S, Van de Wiele T, Guiot Y, Everard A, Rottier O, et al. Changes in gut microbiota control inflammation in obese mice through a mechanism involving GLP-2-driven improvement of gut permeability. Gut. (2009) 58:1091-103. doi: 10.1136/gut.2008.165886

117. Cani PD, Neyrinck AM, Fava F, Knauf C, Burcelin RG, Tuohy $\mathrm{KM}$, et al. Selective increases of bifidobacteria in gut microflora improve high-fat-diet-induced diabetes in mice through a mechanism associated with endotoxaemia. Diabetologia. (2007) 50:2374-83. doi: 10.1007/s00125-007-0791-0

118. Armougom F, Henry M, Vialettes B, Raccah D, Raoult D. Monitoring bacterial community of human gut microbiota reveals an increase 
in Lactobacillus in obese patients and methanogens in anorexic patients. Plos ONE. (2009) 4:e7125.doi: 10.1371/journal.pone. 0007125

119. Kikuchi K, Saigusa D, Kanemitsu Y, Matsumoto Y, Thanai P, Suzuki $\mathrm{N}$, et al. Gut microbiome-derived phenyl sulfate contributes to albuminuria in diabetic kidney disease. Nat Commun. (2019) 10:1835. doi: 10.1038/s41467-019-09735-4

120. Li Y, Su X, Gao Y, Lv C, Gao Z, Liu Y, et al. The potential role of the gut microbiota in modulating renal function in experimental diabetic nephropathy murine models established in same environment. Biochim Biophys Acta (BBA) - Mol Basis Dis. (2020) 1866:165764. doi: 10.1016/j.bbadis.2020.165764

121. Dabke K, Hendrick G, Devkota S. The gut microbiome and metabolic syndrome. J Clin Invest. (2019) 129:4050-7. doi: 10.1172/JCI129194

122. Bano G. Glucose homeostasis, obesity and diabetes. Best Pract Res Clin Obstet Gynaecol. (2013) 27:715-26. doi: 10.1016/j.bpobgyn.2013.02.007

123. Leocádio PCL, Oriá RB, Crespo-Lopez ME, Alvarez-Leite JI. Obesity: more than an inflammatory, an infectious disease? Front Immunol. (2020) 10:3092. doi: $10.3389 /$ fimmu.2019.03092

124. Santacruz A, Marcos A, Wärnberg J, Martí A, Martin-Matillas M, Campoy $\mathrm{C}$, et al. Interplay between weight loss and gut microbiota composition in overweight adolescents. Obesity. (2009) 17:1906-15. doi: 10.1038/oby.2009.112

125. Turnbaugh PJ, Hamady M, Yatsunenko T, Cantarel BL, Duncan A, Ley RE, et al. A core guts microbiome in obese and lean twins. Nature. (2008) 457:480-4. doi: 10.1038/nature07540

126. Payne AN, Chassard C, Zimmermann M, Müller P, Stinca S, Lacroix C. The metabolic activity of gut microbiota in obese children is increased compared with normal- weight children and exhibits more exhaustive substrate utilization. Nutr Diabetes. (2011) 1:e12. doi: 10.1038/nutd.2011.8

127. Muscogiuri G, Cantone E, Cassarano S, Tuccinardi D, Barrea L, Savastano S, et al. Gut microbiota: a new path to treat obesity. Int J Obesity Suppl. (2019) 9:10-9.doi: 10.1038/S41367-019-0011-7

128. Bushman F, Lewis JD, Wu GD. Diet, gut enterotypes and health:is there a link? Nestle Nutr Workshop Ser. (2013)77:65-73. doi: 10.1159/000351385

129. Keim NL, Martin RJ. Dietary whole grain-microbiota interactions: insights into mechanisms for human health. Adv Nutr. (2014) 5:556-7. doi: $10.3945 /$ an.114.006536

130. Xu Z, Knight R. Dietary effects on human gut microbiome diversity. $\mathrm{Br} \mathrm{J}$ Nutr. (2015) 113:S1-S5. doi: 10.1017/S0007114514004127

131. Allcock GH, Allegra M, Flower RJ, Perretti M. Neutrophil accumulation induced by bacterial lipopolysaccharide: effects of dexamethasone and annexin 1. Clin Exp Immunol. (2001) 123:62-7. doi: 10.1046/j.1365-2249.2001.01370.x

132. Csaba P. Kovesdy, Susan L. Furth, Carmine Zoccali, on behalf of the World Kidney Day Steering Committee. Obesity and kidney disease: hidden consequences of the epidemic. Clin Kidney J. (2017) 10:11-8. doi: $10.1093 / \mathrm{ckj} / \mathrm{sfw} 139$

133. Felizardo RJF, Watanabe IKM, Dardi P, Rossoni LV, Câmara NOS. The interplay among gut microbiota, hypertension and kidney diseases: the role of short-chain fatty acids. Pharmacol Res. (2019) 141:366-77. doi: 10.1016/j.phrs.2019.01.019

134. Sorof JM, Lai D, Turner J, Poffenbarger T, Portman RJ. Overweight, ethnicity, and the prevalence of hypertension in school-aged children. Pediatrics. (2004)113(3 Pt 1):475-82. doi: 10.1542/peds.113.3.475

135. De la Cuesta-Zuluaga J, Mueller NT, Álvarez-Quintero R, VelásquezMejía EP, Sierra JA, Corrales-Agudelo V, et al. Higher fecal short-chain fatty acid levels are associated with gut microbiome dysbiosis, obesity, hypertension and cardiometabolic disease risk factors. Nutrients. (2019) 11:51. doi: $10.3390 /$ nu11010051

136. Pluznick JL. Microbial short-chain fatty acids and blood pressure regulation. Curr Hypertens Rep. (2017) 19:25. doi: 10.1007/s11906-017-0722-5

137. Yang T, Richards EM, Pepine CJ, Raizada MK. The gut microbiota and the brain-gut-kidney axis in hypertension and chronic kidney disease. Nat Rev Nephrol. (2018)14:442-56. doi: 10.1038/s41581-018-0018-2

138. Kim S, Rigatto K, Gazzana MB, Knorst MM, Richards EM, Pepine CJ, et al. Altered gut microbiome profile in patients with pulmonary arterial hypertension. Hypertension. (2020) 1:75:1063-71. doi: 10.1161/hypertensionaha.119.14294

139. Koeth RA, Wang Z, Levison BS, Buffa JA, Org E, Sheehy BT, et al. Intestinal microbiota metabolism of L-carnitine, a nutrient in red meat, promotes atherosclerosis. Nat Med. (2013) 19:576-85. doi: 10.1038/nm.3145

140. Barak S, Oettinger-Barak O, Machtei EE, Sprecher H, Ohel G. Evidence of periopathogenic microorganisms in placentas of women with preeclampsia. J Periodontal. (2007) 78:670-76. doi: 10.1902/jop.2007.060362

141. Olaniyi Kehinde S, Moodley J, Mahabeer Y, Mackraj I. Placental microbial colonization and its association with pre-eclampsia. Front Cell Infect Microbiol. (2020) 10:413. doi: 10.3389/fcimb.2020.00413

142. Dunn AB, Hanson L, Vande Vusse L, Leslie S. Through the microbial looking glass: premature labor, preeclampsia, and gestational diabetes: a scoping review. J Perinat Neonatal Nurs. (2019) 33:35-51. doi: 10.1097/JPN.0000000000000375

143. Rustveld LO, Kelsey SF, Sharma R. Association between maternal infections and preeclampsia: A systematic review of epidemiologic studies. Matern Child Health J. (2008). 12:223-42. doi: 10.1007/s10995-007-0224-1

144. Pelzer E, Gomez-Arango LF, Barrett HL, Nitert MD. Maternal health and the placental microbiome. Placenta. (2016) 1:8. doi: 10.1016/j.placenta.2016.12.003

145. Escobar MF, Hincapie MA, Barona JS. Immunological role of the maternal uterine microbiota in postpartum hemorrhage. Front Immunol. (2020) 11:504. doi: 10.3389/fimmu.2020.00504

146. Hampton T. Do gut bacteria play a role in preeclampsia? JAMA. (2020) 2323:2120-21. doi: 10.1001/jama.2020.4755

147. Vaishnavi C. Translocation of gut flora and its role in sepsis. Indian J Med Microbiol. (2013) 31:334-42. doi: 10.4103/0255-0857.118870

148. Adams KM, Lucas J, Kapur RP, Stevens AM. LPS induces translocation of TLR4 in amniotic epithelium. Placenta. (2007) 28:477-81. doi: $10.1016 /$ j.placenta.2006.08.004

149. Gu Y, Lewis DF, Alexander JS, Wang Y. Placenta-derived chymotrypsinlike protease (CLP) disturbs endothelial junctional structure in preeclampsia. Reprod Sci. (2009) 16:479-88. doi: 10.1177/1933719108329818

150. Chaudry IH, Zellweger R, Ayala A. The role of bacterial translocation on Kupffer cell immune function following hemorrhage. Prog Clin Biol Res. (1995) 392:209-18.

151. Perez-Muñoz ME, Arrieta M, Ramer-Tait AE, Walter J. A critical assessment of the "sterile womb" and "in utero colonization" hypotheses: implications for research on the pioneer infant microbiome. Microbiome. (2017) 5:48. doi: 10.1186/s40168-017-0268-4

152. DiGiulio DB, Romero R, Amogan HP, Kusanovic JP, Bik EM, Gotsch F, et al. Microbial prevalence, diversity and abundance in amniotic fluid during preterm labor: a molecular and culture-based investigation. PLOS ONE. (2008) 3:e3056. doi: 10.1371/journal.pone.0003056

153. Aagaard K, Ma J, Antony KM, Ganu R, Petrosino J Versalovic J. The placenta harbors a unique microbiome. Sci Trans Med. (2014) 6:237. doi: 10.1126/scitranslmed.3008599

154. Fuhler GM. The immune system and microbiome in pregnancy. Best Pract Res Clin Gastroenterol. (2020) 44-5:101671. doi: 10.1016/j.bpg.2020.101671

155. Fox C, Eichelberger K. Maternal microbiome and pregnancy outcomes. Fertil Steril. (2015) 104:1358-63. doi: 10.1016/j.fertnstert.2015.09.037

156. Fardini Y, Wang X, Témoin S, Nithianantham S, Lee D, Shoham M, et al. Fusobacterium nucleatum adhesin FadA binds vascular endothelial cadherin and alters endothelial integrity. Mol Microbiol. (2011) 82:1468-80. doi: 10.1111/j.1365-2958.2011.07905.x

157. Giaglis S, Hahn S, Hoesli I, Hasler P. Neutrophil NETs in reproduction: from infertility to preeclampsia and the possibility of fetal loss. Front Immunol. (2012) 3:362. doi: 10.3389/fimmu.2012.00362

158. Fuchs TA, Brill A, Duerschmied D, Schatzberg D, Monestier M, Myers DD, et al. Extracellular DNA traps promote thrombosis. PNAS. (2010) 107:15880-5. doi: 10.1073/pnas.1005743107

159. Stakos DA, Kambas K, Konstantinidis T, Mitroulis I, Apostolidou E, Arelaki S, et al. Expression of functional tissue factor by neutrophil extracellular traps in culprit artery of acute myocardial infarction. Eur Heart J. (2015) 36:1405-14. doi: 10.1093/eurheartj/ ehv007 
160. Levi M, van der Poll T, Schultz M. Systemic versus localized coagulation activation contributing to organ failure in critically ill patients. Semin Immunopathol. (2012) 34:167-79. doi: 10.1007/s00281-011-0283-7

161. Man B, Koenig MD, Bernabe BP, Nagelli U, Tussing-Humphreys L. The role of the gut microbiota in the prevention and management of gestational diabetes mellitus: are we there yet? J Perinatal Neo Nurs. (2020) 34:195-98. doi: 10.1097/JPN.0000000000000497

162. Chen X, Li P, Liu M, Zheng H, He Y, Chen MX, et al. Gut dysbiosis induces the development of pre-eclampsia through bacterial translocation. Gut. (2020) 69:513-22. doi: 10.1136/gutjnl-2019-319101

163. Stavropoulou E, Tsigalou C, Bezirtzoglou E. Functions of the human intestinal microbiota in relation to functional foods. Erciyes Med J. (2018) 40:188-93. doi: 10.5152/etd.2018.18169

164. Power SE, O'Toole PW, Stanton C, Ross RP, Fitzgerald GF. Intestinal microbiota, diet and health. Br J Nutr. (2014) 111:387-02. doi: 10.1017/S0007114513002560

165. Redondo-Useros N, Nova E, González-Zancada N, Díaz LE, GómezMartínez S, Marcos A. Microbiota and lifestyle: a special focus on diet. Nutrients. (2020) 12:1776-83. doi: 10.3390/nu12061776

166. Stavropoulou E, Bezirtzoglou E. Probiotics in medicine: a long debate. Front Immunol. (2020) 11:2192. doi: 10.3389/fimmu.2020.02192

167. Norin KE. Influence of antibiotics on some intestinal microflora associated characteristics. Anaerobe. (1997) 3:145-8. doi: 10.1006/anae.1997.0091

168. Wilck N, Matus MG, Kearney SM, Olesen SW, Forslund K, Bartolomaeus $\mathrm{H}$, et al. Salt-responsive gut commensal modulates TH17 axis and disease. Nature. (2017) 30:551:585-9. doi: 10.1038/nature24628

169. Kiran DMD, Gharat P, Vakharia DM, Ranganathan DN. Specific probiotics for chronic kidney disease: a review. Indian Prac. (2019) 72:22-2.

170. Mack DR, Ahrne S, Hyde L, Wei S, Hollingsworth MA. Extracellular MUC3 mucin secretion follows adherence of Lactobacillus strains to intestinal epithelial cells in vitro. Gut. (2003) 52:827-33. doi: 10.1136/gut.52.6.827

171. Seth A, Yan F, Polk DB, Rao RK. Probiotics ameliorate the hydrogen peroxide- induced epithelial barrier disruption by a PKC- and MAP kinasedependent mechanism. Am J Physiol Gastrointest Liver Physiol. (2008) 294:G1060-9. doi: 10.1152/ajpgi.00202.2007

172. Fayol-Messaoudi D, Berger CN, Coconnier-Polter $\mathrm{MH}$, Liévin-Le Moal V, Servin AL. pH-, Lactic acid-, and non-lactic acid-dependent activities of probiotic Lactobacilli against Salmonella enterica Serovar Typhimurium. Appl Environ Microbiol. (2005) 71:6008-13. doi: 10.1128/AEM.71.10.6008-6013.2005

173. Yoon SS, Sun J. Probiotics, nuclear receptor signaling, and antiinflammatory pathways. Gastroenterol Res Pract. (2011) 2011:971938. doi: 10.1155/2011/971938

174. Corr SC, Li Y, Riedel CU, O’Toole PW, Hill C, Gahan CGM. Bacteriocin production as a mechanism for the antiinfective activity of Lactobacillus salivarius UCC118. Proc Nat Acad Sci. (2007) 104:7617-21. doi: 10.1073/pnas.0700440104

175. Philip M. Sherman, Kathene C. Johnson-Henry, Helen P. Yeung, Peter S. C. Ngo, Jacques Goulet, Thomas A. Tompkins. Probiotics reduce enterohemorrhagic Escherichia coli O157:H7- and enteropathogenic E. coli O127:H6-induced changes in polarized T84 epithelial cell monolayers by reducing bacterial adhesion and cytoskeletal rearrangements. Inf Immun. (2005) 73:5183-8. doi: 10.1128/IAI.73.8.5183-5188.2005

176. Delzenne NM, Neyrinck AM, Backhed F, Cani PD. Targeting gut microbiota in obesity: effects of prebiotics and probiotics. Nature Rev Endocrinol. (2011) 7:639-46. doi: 10.1038/nrendo.2011.126

177. Pavlovic N, Stankov K, Mikov M. Probiotics-interactions with bile acids and impact on cholesterol metabolism. Appl Biochem Biotechnol. (2012)168:1880-95. doi: 10.1007/s12010-012-9904-4
178. Markowiak-Kopeć P, Slizewska K. The effect of probiotics on the production of short-chain fatty acids by human intestinal microbiome. Nutrients. (2020) 12:1107. doi: 10.3390/nu12041107

179. Bartolomaeus H, Balogh A, Yakoub M, Homann S, Markó L, Höges $S$, et al. Short-chain fatty acids: a link between prebiotics and microbiota in chronic kidney disease. Circulation. (2019) 139:1407-21. doi: 10.1161/CIRCULATIONAHA.118.036652

180. Sirich TL, Plummer NS, Gardner CD, Hostetter TH, Meyer TW. Effect of increasing dietary fiber on plasma levels of colon-derived solutes in hemodialysis patients. Clin J Am Soc Nephrol. (2014) 9:1603-10. doi: 10.2215/CJN.00490114

181. Rossi M, Johnson DW, Morrison M, Pascoe EM, Coombes JS, Forbes JM, et al. Synbiotics easing renal failure by improving gut microbiology (SYNERGY): a randomized trial. Clin J Am Soc Nephrol. (2016) 11:223-31. doi: 10.2215/CJN.05240515

182. Hurst NR, Kendig DM, Murthy KS, Grider JR. The short chain fatty acids, butyrate and propionate, have differential effects on the motility of the guinea pig colon. Neurogastroenterol Motil. (2014) 26:1586-96. doi: $10.1111 / \mathrm{nmo} .12425$

183. Bourlioux P. Faecal microbiota transplantation: key points to consider. Annales Pharmaceutiques Françaises. (2015) 73:163-8. doi: 10.1016/j.pharma.2015.02.001

184. Cammarota G, Ianiro G, Tilg H, Rajilić-Stojanović M, Kump P, Satokari R, et al. European consensus conference on faecal microbiota transplantation in clinical practice. Gut. (2017) 66:569-80. doi: 10.1136/gutjnl-2016-313017

185. Konturek PC, Koziel J, Dieterich W, Haziri D, Wirtz S, Glowczyk I, et al. Successful therapy of Clostridium difficile infection with fecal microbiota transplantation. J Physiol Pharmacol. (2016) 67:859-66

186. Ianiro G, Rossi E, Thomas AM, Schinzari G, Masucci L, Quaranta G, et al. Faecal microbiota transplantation for the treatment of diarrhoea induced by tyrosine-kinase inhibitors in patients with metastatic renal cell carcinoma. Nature Comm. (2020) 11:4333. doi: 10.1038/s41467-020-18127-y

187. Hatakeyama S, Yamamoto H, Okamoto A, Imanishi K, Tokui N, Okamoto T, et al. Effect of an oral adsorbent, AST-120, on dialysis initiation and survival in patients with chronic kidney disease. Int J Nephrol. (2012) 2012:376128. doi: 10.1155/2012/376128

188. Lekawanvijit S, Kumfu S, Wang BH, Manabe M, Nishijima F, Kelly DJ, et al. The uremic toxin adsorbent AST-120 abrogates cardiorenal injury following myocardial infarction. PLoS ONE. (2013) 8:e83687. doi: 10.1371/journal.pone.0083687

189. Nakamura T, Sato E, Fujiwara N, Kawagoe Y, Suzuki T, Ueda Y, et al. Oral adsorbent AST-120 ameliorates tubular injury in chronic renal failure patients by reducing proteinuria and oxidative stress generation. Metabolism. (2011) 60:260-4. doi: 10.1016/j.metabol.2010.01.023

190. Fricke WF, Maddox C, Song Y, Bromberg JS. Human microbiota characterization in the course of renal transplantation. Am J Transplant. (2014) 14:416-27. doi: 10.1111/ajt.12588

Conflict of Interest: The authors declare that the research was conducted in the absence of any commercial or financial relationships that could be construed as a potential conflict of interest.

Copyright (c) 2021 Stavropoulou, Kantartzi, Tsigalou, Konstantinidis, Romanidou, Voidarou and Bezirtzoglou. This is an open-access article distributed under the terms of the Creative Commons Attribution License (CC BY). The use, distribution or reproduction in other forums is permitted, provided the original author(s) and the copyright owner(s) are credited and that the original publication in this journal is cited, in accordance with accepted academic practice. No use, distribution or reproduction is permitted which does not comply with these terms. 